\title{
Transient effects caused by gas depletion during carbon dioxide electroreduction
}

\author{
Álvaro Moreno Soto, ${ }^{*} \dagger$ Jack R. Lake and Kripa K. Varanasi* \\ Department of Mechanical Engineering, Massachusetts Institute of Technology, 77 Massachusetts Avenue, Cambridge, \\ Massachusetts 02139, USA \\ $\dagger$ Current address: Aerospace Engineering Research Group, Universidad Carlos III de Madrid, Avenida de la Universidad \\ 30, Leganés, 28911, Comunidad de Madrid, Spain \\ *E-mail: amsoto@ing.uc3m.es, varanasi@mit.edu
}

\section{Activation and cleaning of Nafion membrane}

The Nafion membrane used in our experiments was purchased at Fuel Cell Store. Prior to the experiments, it needs to be activated to allow for the transmission of ions from one half of the $\mathrm{H}$-cell to the other, but at the same time inhibit the passage of other species, such as gaseous and liquid products obtained from CO2RR. The following procedure, based on our experience and a combination of previously described methods from literature ${ }^{1-5}$, indicates the steps taken to achieve a successful activation of the Nafion membrane:

1. Boiling in $3 \% \mathrm{H}_{2} \mathrm{O}_{2}$ (hydrogen peroxide) for $1 \mathrm{~h}$.

2. Submersion in $0.1 \mathrm{M} \mathrm{H}_{2} \mathrm{SO}_{4}$ (sulfuric acid) overnight.

3. Boiling in DI water for $1 \mathrm{~h}$.

4. Sonication in $0.1 \mathrm{M} \mathrm{KClO}_{4}$ (potassium perchlorate) for $30 \mathrm{~min}$.

5. Thorough rinse with DI water.

The Nafion layer should be kept submerged in DI water until necessary. To ensure that the cleaning process has been successfully accomplished, we track the appearance of bubbles on the membrane while it is resting prior to the experiments: a properly cleaned and activated membrane will lack bubbles attaching to its surface.

\section{Preparation of electrocatalysts}

As explained in the main text, copper, silver and gold were selected as electrocatalysts for our study due to their accessibility and selectivity to different products from CO2RR. To summarize, Ag and $\mathrm{Au}$ are very selective to $\mathrm{CO}$ whereas $\mathrm{Cu}$ provides a wide variety of liquid and gaseous products, including high-carbon components $\left(\mathrm{C}_{2,3}\right)$. To guarantee that the electrodes are at optimal conditions to perform CO2RR, each follows a specific preparation process due to the different ways in which each material reacts with its environment at standard conditions. To be more specific, copper spontaneously forms an oxide layer which covers its surface within minutes of being exposed to ambient air, whereas silver and gold are relatively stable and remain pure if they are kept submerged in DI water. We dedicate a specific subsection for each material used in this research.

\subsection{Preparation of $\mathrm{Cu}$ electrodes}

$\mathrm{Cu}$ wire of $99.999 \%$ purity was purchased from Sigma-Aldrich. In this state, $\mathrm{Cu}$ is a material which is highly susceptible to oxidation, i.e. CuO appears within minutes on its surface ${ }^{6}$. Therefore, in order to ensure that CO2RR occurs on a $\mathrm{Cu}$ wire with the least experimentally achievable oxide layer blocking the access to the pure electrocatalyst, a process known as electropolishing is performed $^{7}$. For that, we introduce the $\mathrm{Cu}$ coil in a phosphoric acid solution ( $>85 \mathrm{wt} . \%$ in $\mathrm{H}_{2} \mathrm{O}$ ) and use a carbon rod as counter electrode. With a VSP potentiostat (BioLogic) and using the counter electrode also as the reference electrode, we perform a cyclic voltammogram (CV) from 0 to $3 \mathrm{~V}$. At approximately $2 \mathrm{~V}$ (depending on the state of the $\mathrm{Cu}$ electrode, the amount of $\mathrm{CuO}$ deposited on top 
(a)

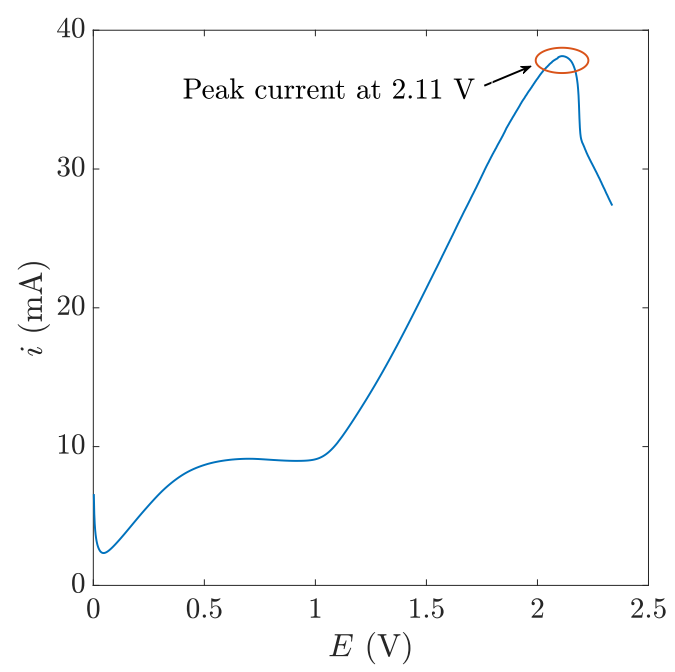

(b)

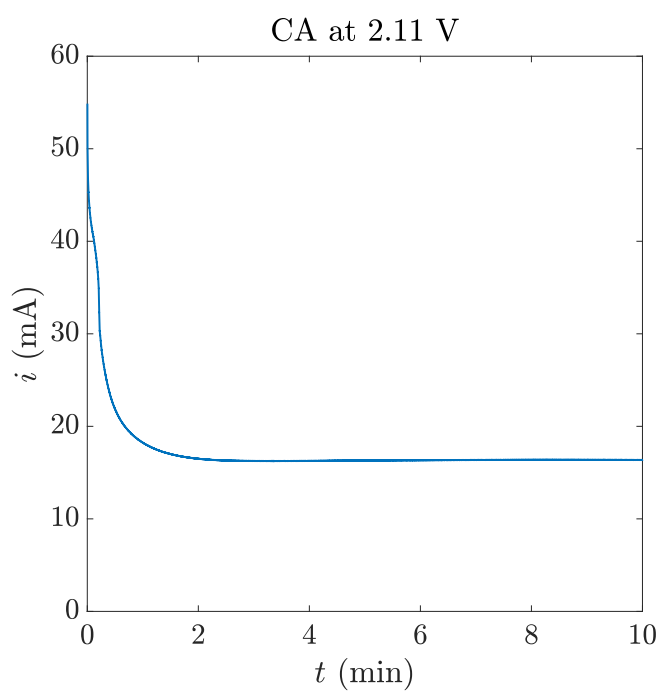

Figure S1 (a) CV to determine the voltage at which the peak current for the first step of the electropolishing procedure of $\mathrm{Cu}$ in a phosphoric acid solution occurs. (b) Final step of the electropolishing procedure: CA ran at the voltage at which the peak current in the previous CV is obtained. We can clearly see that the $\mathrm{Cu}$ wire has been fully electropolished after approximately 3 minutes of reaction (a steady-state condition is reached).

and the volume of electrolyte used), the current will reach a maximum and then drop (see Figure S1a). Afterwards, we run a chronoamperometry (CA) experiment for 10 minutes at the voltage in which the peak current occurred in the previous CV, Figure S1b. The electrode will be ready once it is rinsed with DI water after the $\mathrm{CA}$. We have already mentioned that $\mathrm{CuO}$ may appear very rapidly in standard conditions, therefore CO2RR experiments were carried out immediately following the electropolishing procedure.

(a)

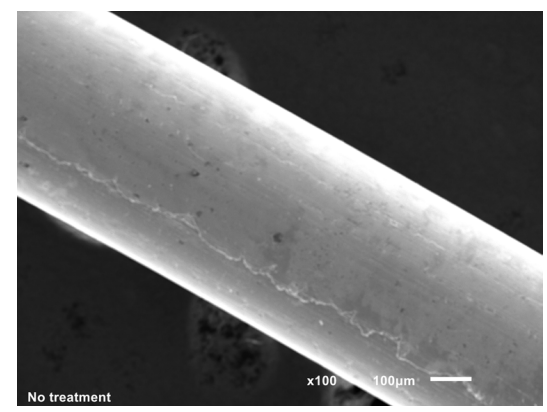

(b)

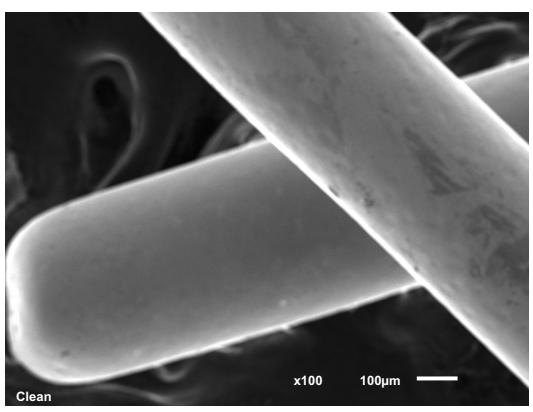

(c)

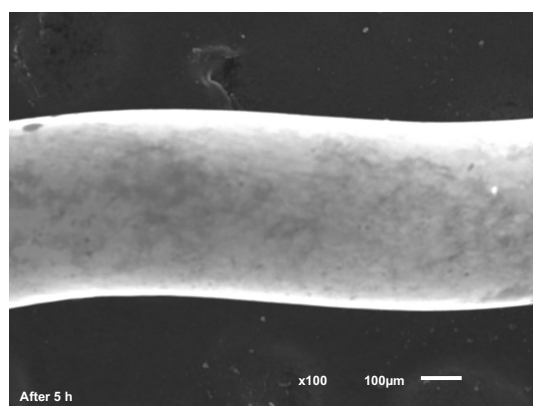

Figure S2 SEM images of the state of the Cu electrode (a) prior to and (b) after the cleaning process, and (c) after experiments. The magnification for the three images is 100 times and the scale bar represents 100 $\mu \mathrm{m}$. There is clear evidence of the significant importance of the cleaning procedure to ensure an optimal $\mathrm{CO}_{2}$ electroreduction. The detrimental effect of long-term exposure of copper to an aqueous reacting media can be observed by the visible deterioration of the electrode surface after a very long reaction.

SEM (Scanning Electron Microscope) images of the electrode surface before and after the cleaning procedure and after experiments were done are shown in Figure S2. There is a significant improvement of the electrode condition after the cleaning prior to experiments, in which results from EDS (Energy Dispersive X-ray Spectroscopy) show that Figure S2a (before cleaning) only presents 


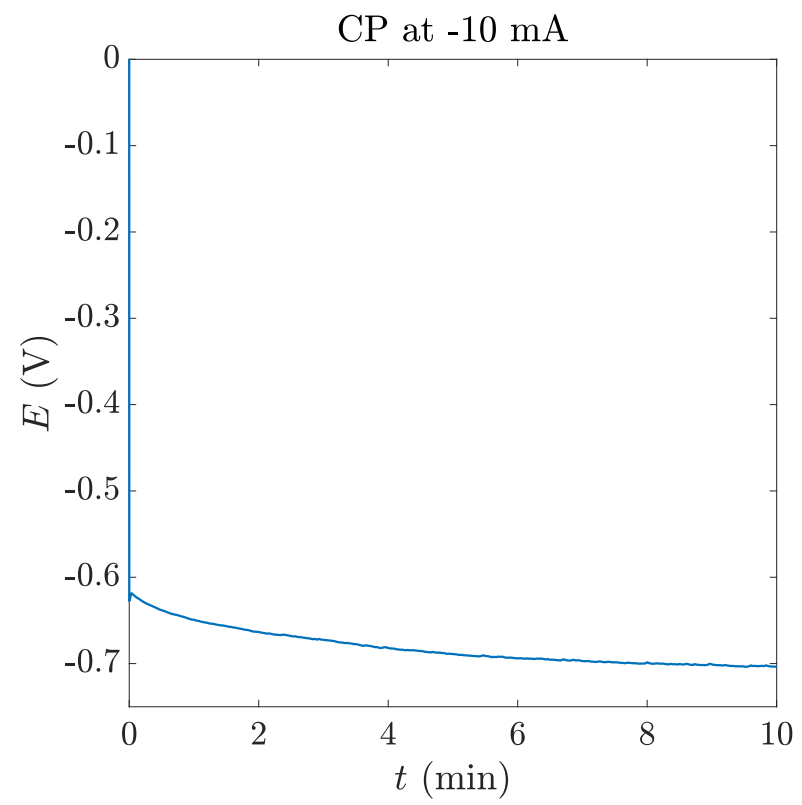

Figure S3 Chronopotentiometry experiment at $-10 \mathrm{~mA}$ on an $\mathrm{Ag}$ wire of $2.36 \mathrm{~cm}^{2}$ surface area in a $\mathrm{H}_{2} \mathrm{SO}_{4}$ solution using $\mathrm{Pt}$ and $\mathrm{Ag} / \mathrm{AgCl}$ as counter and reference electrode, respectively. $\mathrm{H}_{2}$ bubbles were vigorously generated during 10 minutes to actively remove contamination within the interstices of the electrode. The potential $E$ is referred to an $\mathrm{Ag} / \mathrm{AgCl}$ electrode.

a $92 \%$ purity (with presence of other contaminants such as oxides and silica), whereas Figure S2b shows indeed a purity of $99 \% \mathrm{Cu}$. However, and as indicated before, copper is a very sensitive material which rapidly oxidizes, with oxidation beginning as soon as the electrode is introduced into the liquid electrolyte. After an experiment of 5 hours, Figure S2c, the purity of the electrode has decreased to $95 \%$. This is, together with the effect of gas depletion, one of the factors which contribute to the poor long-term performance of $\mathrm{Cu}$ electrodes as compared to other more stable materials such as silver or gold.

\subsection{Preparation of Ag electrodes}

$\mathrm{Ag}$ wire of $99.999 \%$ purity was purchased from Sigma-Aldrich. Even though silver is generally a very stable material, it can react when exposed to air and form silver sulfide $\left(\mathrm{Ag}_{2} \mathrm{~S}\right)$ and oxide $\left(\mathrm{Ag}_{2} \mathrm{O}\right)^{8}$. While performing $\mathrm{CO} 2 \mathrm{RR}, \mathrm{Ag}$ is also known to absorb hydrocarbons, which may affect the electrocatalysis efficiency ${ }^{9}$. Therefore, active generation of hydrogen bubbles within the interstices of the Ag wire may remove the initial layer of sulfide / oxide while delaying the absorption of hydrocarbons ${ }^{10,11}$. The following procedure is performed accordingly to condition the electrode for CO2RR: first, the Ag wire is sonicated in ethanol for 10 minutes in order to weaken the bond between the sulfide / oxide layer to the pure electrocatalyst. This step is followed by a 5-minute sonication in DI water to facilitate the removal of that layer. Afterwards, the wire is submerged into a sulfuric acid solution (puriss. p.a., $\geq 25 \%$, Sigma-Aldrich) using Pt as counter electrode and an $\mathrm{Ag} / \mathrm{AgCl}$ reference electrode (both from Pine Research Instrumentation). To generate a significant amount of $\mathrm{H}_{2}$ bubbles, we run a chronopotentiometry (CP) cycle at -10 mA (the current could be ramped up to $-15 \mathrm{~mA}$ if necessary) for 10 minutes (see Figure S3), followed by a 10minute sonication in DI water. The electrode is used directly after the cleaning procedure. After the experiments, the electrode would be kept in DI water to avoid oxidation by exposing the metal surface directly to air.

Again, SEM images are presented in Figure S4. In this case, the electrode already comes in a very good condition directly from the manufacturer, Figure S4a, showing almost $99 \%$ purity (with a very small presence of other contaminants such as silica). The cleaning process nevertheless im- 
(a)

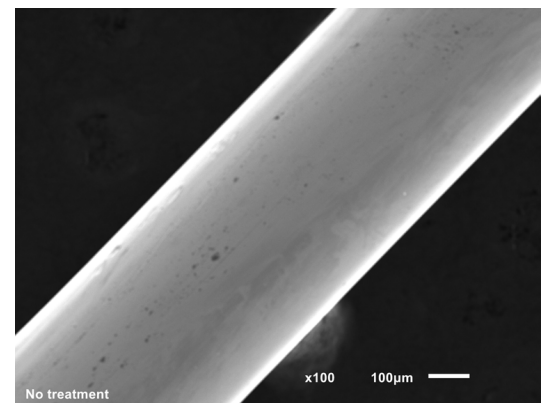

(b)

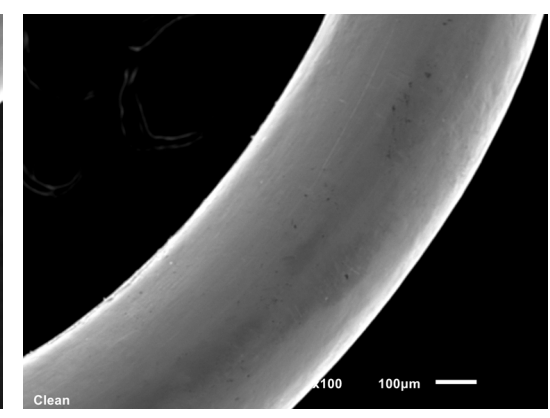

(c)

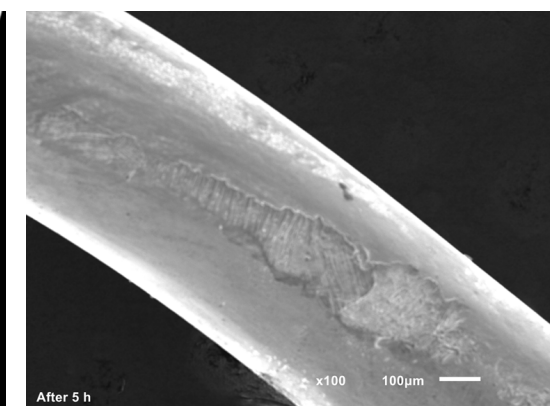

Figure S4 SEM images of the state of the Ag electrode (a) prior to the cleaning process, (b) after cleaning and (c) after experiments. The magnification for the three images is 100 times and the scale bar represents $100 \mu \mathrm{m}$. The damage caused by a long lasting $\mathrm{CO}_{2}$ electroreduction can be clearly depicted.

proves the electrocatalyst purity to more than $99.5 \%$, Figure S4b. The long reacting time damages the surface of the electrode, Figure S4c, which is now contaminated by the deposition of carbon particles on its surface. Still, the purity remains higher than $98.5 \%$, which is important to the stability of the long-term reaction. However, this purity may not be sufficient if the same electrode needs to be used for much longer times.

\subsection{Preparation of Au electrodes}

Gold, as well as Pt, are among the most stable materials used in chemical reactions, since they are not easily corrupted or contaminated. 99.999 \%-purity gold wire from Sigma-Aldrich was used to perform CO2RR. Even though Au is very stable, the electrode needs to be preconditioned before experiments are performed, since there may be contaminating particles on its surface from its exposure to ambient air. Whereas the purpose of the cleaning procedure for $\mathrm{Cu}$ and $\mathrm{Ag}$ are dedicated to remove sulfide or oxide layers that may be deposited on the electrocatalyst, the procedure for $\mathrm{Au}$ only involves dirt removal and surface conditioning.

First, we sonicate the wire in DI water for 10 minutes. In order to condition the surface of the electrode ${ }^{12,13}$, we run two subsequent CVs in different media: to adapt the gold surface to the liquid medium (electrolyte) in which CO2RR is going to take place, we implement a CV from -200 $\mathrm{mV}$ to $-1200 \mathrm{mV}$ at $50 \mathrm{mV} \mathrm{s}^{-1}$ for 10 cycles in a $0.1 \mathrm{M} \mathrm{KHCO}_{3}$ solution ${ }^{14,15}$, see Figure S5a; to adapt the electrode to the potential production of $\mathrm{H}_{2}$ gas and to remove contaminants from within its interstices, a CV from $-400 \mathrm{mV}$ to $1400 \mathrm{mV}$ at $100 \mathrm{mV} / \mathrm{s}$ for 10 cycles in a $\mathrm{H}_{2} \mathrm{SO}_{4}$ solution (puriss. p.a. $\geq 25 \%$, Sigma-Aldrich) is carried out, Figure S5b. The surface chemistry for this last CV shows that in the negative potential zone and moving towards more negative potential, the electrode surface adsorbs $\mathrm{H}$., whereas looping back towards more positive values indicates $\mathrm{H}$. desorption from the Au surface ${ }^{12,13}$. For both $\mathrm{CVs}$, a Pt and $\mathrm{Ag} / \mathrm{AgCl}$ counter and reference electrode are respectively used. As a final step, we sonicate the Au wire in DI water for 10 minutes. After experiments, the Au electrode is kept in DI water to avoid contact with open air.

This cleaning procedure is critical to obtain optimal results from our CO2RR experiments. SEM images are shown in Figure S6 from the electrode state before and after the cleaning procedure and after experiments are done. There is clearly a significant improvement from the electrode condition after the cleaning prior to experiments, in which results from EDS show that Figure S6a (before cleaning) only presents a $92 \%$ purity (with presence of other contaminants such as carbon, oxygen and calcium), whereas Figures S6b and S6c present indeed more than 99\% Au (without remarkable differences between the two of them). A proper cleaning process is therefore critical to obtain optimal results from our chemical process. 
(a)

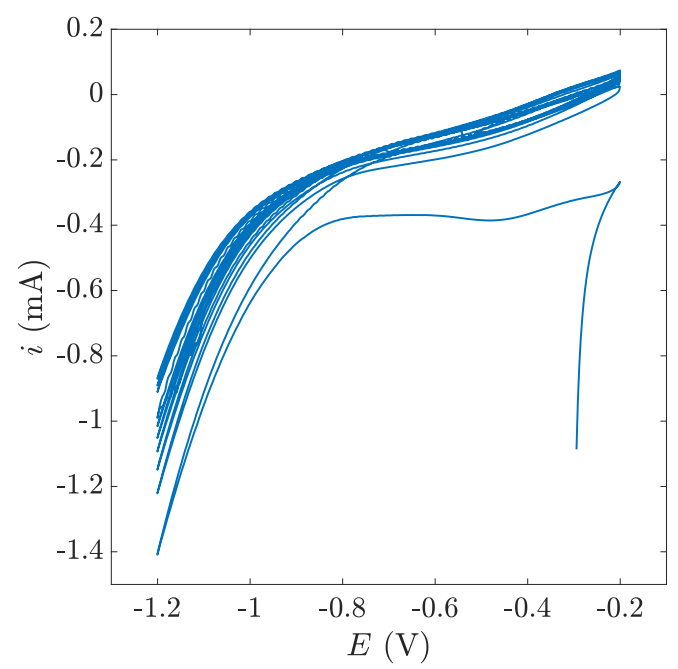

(b)

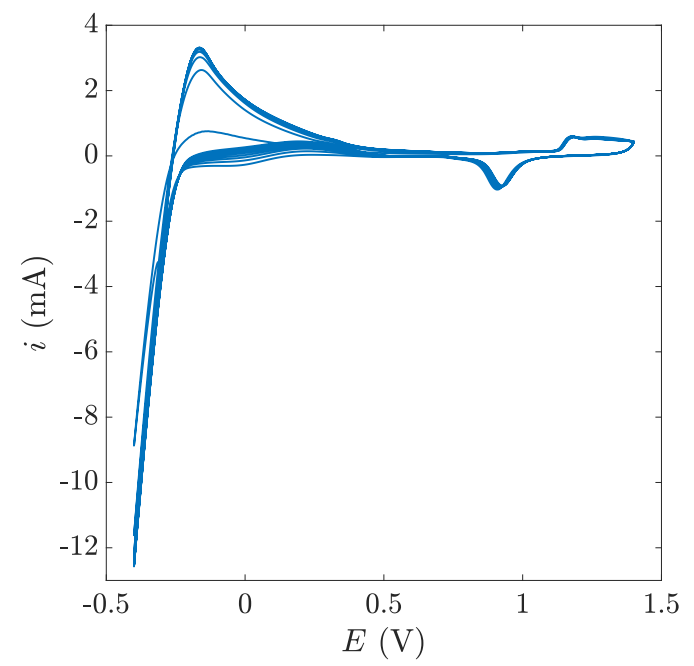

Figure S5 (a) First step of the conditioning procedure for gold electrodes: CV from -200 mV to $-1200 \mathrm{mV}$ at $50 \mathrm{mV} \mathrm{s}^{-1}$ for 10 cycles in $0.1 \mathrm{M} \mathrm{KHCO}_{3}$. After a couple of cycles, stability is reached. (b) Second step of the conditioning procedure: $\mathrm{CV}$ from $-400 \mathrm{mV}$ to $1400 \mathrm{mV}$ at $100 \mathrm{mV} \mathrm{s}^{-1}$ for 10 cycles in a $\mathrm{H}_{2} \mathrm{SO}_{4}$ solution. In the negative potential regime, when voltage is looping towards more negative values, $\mathrm{H}$. protons are adsorbed into the metal, whereas moving towards positive potential they are desorbed ${ }^{12,13}$. The potential $E$ is referred to an $\mathrm{Ag} / \mathrm{AgCl}$ electrode.

(a)

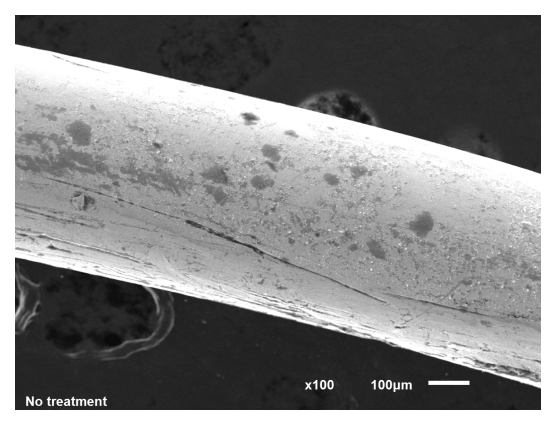

(b)

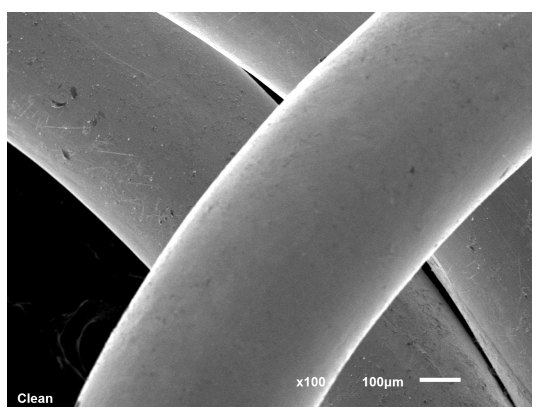

(c)

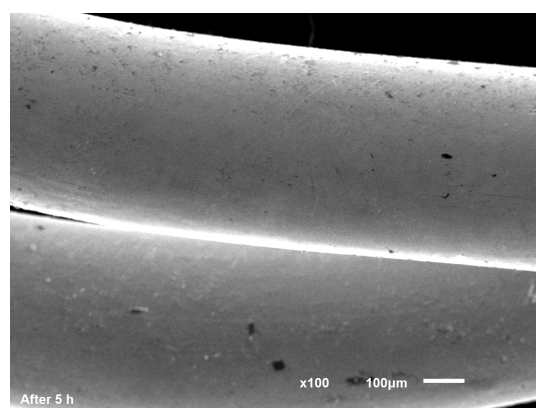

Figure S6 SEM images of the surface state of the Au electrode (a) prior to (b) and after the cleaning process, and (c) after experiments. The magnification for the three images is 100 times and the scale bar represents $100 \mu \mathrm{m}$. The cleaning procedure ensures an optimal condition to perform $\mathrm{CO}_{2}$ electroreduction. The stability remains after the experiments due to the intrinsic properties of the material. 


\section{Calculation of the different $F_{\text {eff }}$ for CO2RR}

The calculation of the Faradaic efficiencies for the different products obtained during CO2RR is based on Faraday's law of electrolysis, namely Equation (2) in the main text:

$$
i=\frac{m F z}{M t}=\frac{n F z}{t},
$$

where $m$ is the mass of the product, $F=96485 \mathrm{C} \mathrm{mol}^{-1}$ is Faraday's constant, $z$ is the valence of the reaction, $M$ is the molecular weight of the product, $n$ the corresponding number of moles and $t$ the reaction time. By this equation, we can use the measured molar amount of each product that is generated from the chemical reaction and calculate the corresponding partial current $i_{\text {partial }}$. There is however a different methodology depending on the instrumental by which the different components are measured.

\subsection{The analysis of GC data}

The Gas Chromatographer takes a sample of gas from our H-cell every 14 minutes, and measures the molar parts per million (ppm) of each detected component following a calibration chart based on the analysis of a customized gas precision calibration mixture (Gasco and Shopcross). Those ppm values can be translated into molar fractions, i.e. $x_{i}=\mathrm{ppm}_{\mathrm{i}} / \mathrm{ppm}_{\mathrm{total}}$, where subindex $i$ stands for the different products.

To flow the produced gas samples for analysis into the GC loop, $\mathrm{CO}_{2}$ is flown through the working electrode side of the H-cell. The analyte gas stream passes through the GC sample loop at a constant flow rate of $20 \mathrm{sccm}$ that we control via a digital flowmeter (Cole-Parmer). According to the ideal gas law, $P V=n R T$ (where $P$ is the pressure in $\mathrm{Pa}, V$ the volume in $\mathrm{m}^{3}, R=8.31442 \mathrm{~J}$ $\mathrm{mol}^{-1} \mathrm{~K}^{-1}$, and $T$ the temperature in $\mathrm{K}$ ), at standard conditions and given the volume, the number of moles can be calculated. Indeed, the measurement of the flow rate, $\dot{V}$, can be readily used to calculate $\dot{n}$ as $\dot{n}=P \dot{V} /(R T)$. By knowing the molar fractions $x_{i}$, we can calculate the partial molar rate $\dot{n}_{i}=\dot{n} x_{i}$ for each component of the reaction.

Once each partial molar rate is known, we can rewrite Faraday's law conveniently:

$$
i=\frac{m F z}{M t}=\dot{n} F z
$$

Finally, the Faradaic efficiency for each product can be directly calculated:

$$
F_{\text {eff }, \mathrm{i}}=\frac{i_{\text {partial }, \mathrm{i}}}{i_{\text {total }}}=\frac{\dot{n}_{i} F z_{i}}{i_{\text {total }}}
$$

\subsection{The analysis of NMR data}

NMR is exclusively dedicated to the analysis of liquid products. Samples of $700 \mu 1$ are pipetted in NMR glass tubes and mixed with $35 \mu 1100 \mathrm{mM}$ DMSO and $100 \mathrm{mM}$ phenol in $\mathrm{D}_{2} \mathrm{O}$ standard (for calibration purposes). The report obtained after the analysis with a Bruker 402 instrument is then interpreted with the software MestReNova. Such a file contains the frequencies where the device could detect electron vibrations within each of the liquid components. Therefore, peaks at certain frequencies correspond to the presence of a certain liquid. By knowing the exact concentration of the calibration liquid, we can compare the areas under those peaks with the areas corresponding to the calibration products. The ratio between those areas is an indicative of the concentration of a certain product $i$ within the liquid sample. This ratio depends on the product, and therefore, multiple experiments had to be done to calculate the proportionality between the areas corresponding to a certain product and the calibrating components. Once those proportions are found and the calibration constants have been calculated, we can obtain the desired concentrations.

Once we have measured a certain product molar concentration and given the total volume of liquid used for the experiments (35 $\mathrm{ml}$ in our case), the total amount of moles produced during 
the reaction can be determined. Again, we only need to input the time at which the sample was taken, the number of moles and the valence of the reaction into Faraday's law, Equation (S2), to compute the partial current dedicated to generate such product. Once this is known, $F_{\text {eff }}$ can be directly obtained by diving $i_{\text {partial }}$ by $i_{\text {total }}$.

\section{Solution of the equilibrium system of equations for $\mathbf{C O}_{2}$ dissolution}

For convenience, we write in the following the equilibrium equations for $\mathrm{CO}_{2}$ dissolution in an aqueous solution of moderate ionic strength ${ }^{16-19}$ :

$$
\begin{gathered}
\mathrm{CO}_{2}(\mathrm{~g}) \leftrightarrow \mathrm{CO}_{2}(\mathrm{aq}) \text { with } p K_{0}=-2622.38 / T-0.0178471 \times T+15.5873 \\
\mathrm{CO}_{2}(\mathrm{aq})+\mathrm{H}_{2} \mathrm{O} \leftrightarrow \mathrm{H}^{+}+\mathrm{HCO}_{3}^{-} \text {with } p K_{1}=3404.71 / T+0.032786 \times T-14.8435 \\
\mathrm{HCO}_{3}^{-} \leftrightarrow \mathrm{H}^{+}+\mathrm{CO}_{3}^{-2} \text { with } p K_{2}=2902.39 / T+0.02379 \times T-6.4980 \\
\mathrm{H}_{2} \mathrm{O} \leftrightarrow \mathrm{H}^{+}+\mathrm{OH}^{-} \text {with } K_{w}=\exp (148.9802-13847.26 / T-23.6521 \log (T))
\end{gathered}
$$

The equilibrium constants are defined both in their $K$ and $p K$ form, being both parameters related by $K=10^{-p K}$. $T$ corresponds to the absolute temperature in Kelvin.

We analyze in the following each formula independently. Equation (S4) corresponds to Henry's law $^{20,21}$ :

$$
\left[\mathrm{CO}_{2}(\mathrm{aq})\right]=K_{0} P
$$

where magnitudes between brackets indicate concentration. Equation (S5) can be expressed in terms of concentrations and the corresponding equilibrium constant:

$$
K_{1}\left[\mathrm{H}_{2} \mathrm{CO}_{3}\right]=\left[\mathrm{H}^{+}\right]\left[\mathrm{HCO}_{3}^{-}\right]
$$

$\mathrm{H}_{2} \mathrm{CO}_{3}$ stands for the carbonic acid which is generated by the dissolution of $\mathrm{CO}_{2}$ in water. Generally, this amount will be significantly lower than the total $\mathrm{CO}_{2}(\mathrm{aq})$. However, under steady state conditions, it can be assumed that $\mathrm{CO}_{2}(\mathrm{aq})$ equals the total carbonic acid in the solution, i.e. [ $\left.\mathrm{CO}_{2}(\mathrm{aq})\right]$ $=\left[\mathrm{H}_{2} \mathrm{CO}_{3}\right]$. Similarly, Equation (S6):

$$
K_{2}\left[\mathrm{HCO}_{3}^{-}\right]=\left[\mathrm{H}^{+}\right]\left[\mathrm{CO}_{3}^{-2}\right],
$$

and finally Equation (S7):

$$
K_{w}=\left[\mathrm{H}^{+}\right]\left[\mathrm{OH}^{-}\right] .
$$

One more equation is needed to close the system: ion neutrality. This equation enforces neutral charge in the solution to guarantee stability in the absence of an electric field:

$$
\left[\mathrm{HCO}_{3}^{-}\right]+2\left[\mathrm{CO}_{3}^{-2}\right]+\left[\mathrm{OH}^{-}\right]=\left[\mathrm{K}^{+}\right]+\left[\mathrm{H}^{+}\right] .
$$

Combining Equations (S8) - (S12), a single equation is reached:

$$
\left[\mathrm{H}^{+}\right]^{3}+\left[\mathrm{K}^{+}\right]\left[\mathrm{H}^{+}\right]^{2}-\left(K_{1} K_{0} P+K_{w}\right)\left[\mathrm{H}^{+}\right]-2 K_{2} K_{1} K_{0} P=0
$$

which corresponds to Equation (5) in the main text and that can be readily solved knowing that $P=1 \mathrm{~atm}$ (standard conditions), $T=293.15 \mathrm{~K}$ and $\mathrm{K}^{+}=0.1 \mathrm{M}$ from a $0.1 \mathrm{M} \mathrm{KHCO}_{3}$ electrolyte solution. The unknown $\left[\mathrm{H}^{+}\right]$can be directly calculated and automatically associated to $\mathrm{pH}$ by $\mathrm{pH}=-\log \left(\left[\mathrm{H}^{+}\right]\right)$. For a $\mathrm{CO}_{2}$ saturated electrolyte, a $\mathrm{pH}$ level of 6.79 is determined. 


\section{Equilibrium state recovery after $\Delta \mathrm{OH}^{-}$and / or $\Delta \mathrm{CO}_{2}$}

For a carbonated solution system in equilibrium, the concentration of ions is determined by the environmental conditions (temperature $T$ and pressure $P$ ), the salt concentration in the system (salt molarity in dissolution) and the gas saturation level. In the previous section, we described the equilibrium equations for a $0.1 \mathrm{M} \mathrm{KOH}$ solution saturated with $\mathrm{CO}_{2}$ at standard conditions, i.e. $0.1 \mathrm{M} \mathrm{KHCO}_{3}$ solution. In such a case, the equilibrium concentration of each carbonic derivative corresponds to:

$$
\begin{array}{r}
{\left[\mathrm{CO}_{2}(\mathrm{aq})\right]=0.0394 \mathrm{M} \quad\left[\mathrm{HCO}_{3}^{-}\right]=0.0999 \mathrm{M} \quad\left[\mathrm{CO}_{3}^{-2}\right]=2.563 \times 10^{-5} \mathrm{M}} \\
{\left[\mathrm{OH}^{-}\right]=4.176 \times 10^{-8} \mathrm{M} \quad\left[\mathrm{H}^{+}\right]=1.638 \times 10^{-7} \mathrm{M}}
\end{array}
$$

with the last concentration obeying $\mathrm{pH}=-\log \left(\left[\mathrm{H}^{+}\right]\right)$.

When a reaction starts, there is a sudden increase in the ionic concentration of $\mathrm{OH}^{-}$originated by the release of electrons and protons, i.e. for each proton and electron consumed in the reaction to recombine and generate the CO2RR products, there is a hydroxide ion being released into the system (proton balance) ${ }^{22}$. Therefore, a sudden increase in that concentration triggers the compensating mechanisms to bring back the solution to an equilibrium state. This similarly occurs when $\mathrm{CO}_{2}$ is being consumed at the electrode and therefore its concentration decreases. As the solution becomes more basic, i.e. higher $\left[\mathrm{OH}^{-}\right]$or lower $\left[\mathrm{CO}_{2}(\mathrm{aq})\right]$, the equilibrium Equations (S4 - S7) can be rewritten in their conjugated form:

$$
\begin{gathered}
\mathrm{CO}_{2}(\mathrm{~g}) \leftrightarrow \mathrm{CO}_{2}(\mathrm{aq}) \text { equals Equation (S4) } \\
\mathrm{CO}_{2}(\mathrm{aq})+\mathrm{OH}^{-} \leftrightarrow \mathrm{HCO}_{3}^{-}+\mathrm{H}_{2} \mathrm{O} \text { with } K_{b 1} \\
\mathrm{HCO}_{3}^{-}+\mathrm{OH}^{-} \leftrightarrow \mathrm{CO}_{3}^{-2}+\mathrm{H}_{2} \mathrm{O} \text { with } K_{b 2} \\
\mathrm{H}_{3} \mathrm{O}^{+}+\mathrm{OH}^{-} \leftrightarrow 2 \mathrm{H}_{2} \mathrm{O} \text { with } K_{w}
\end{gathered}
$$

$\mathrm{H}_{3} \mathrm{O}^{+}$stands for the hydronium ion and is equivalent to an aqueous cation / proton. The equilibrium constants $K_{b 1}$ and $K_{b 2}$ are the conjugates of $K_{1}$ and $K_{2}$, respectively, and follow $K_{w}=K_{i} K_{b i}$.

Let's name $A, B, C, D, E$ and $F$ the equilibrium concentrations $\left[\mathrm{CO}_{2}(\mathrm{aq})\right],\left[\mathrm{HCO}_{3}^{-}\right],\left[\mathrm{CO}_{3}^{-2}\right],\left[\mathrm{OH}^{-}\right]$, $\left[\mathrm{H}_{3} \mathrm{O}^{+}\right]$and $\left[\mathrm{H}_{2} \mathrm{O}\right]$, respectively. When a sudden change in the concentration of hydroxide ions $\Delta \mathrm{OH}^{-}$or a decrease in reactant concentration $\Delta \mathrm{CO}_{2}$ occurs, each Equation (S16 - S18) needs to equilibrate by increasing or decreasing the amount of existing ions in solution. Having $x_{1}, x_{2}$ and $x_{3}$ represent the unknown concentration changes that Equations (S16), (S17) and (S18) respectively entail, we can write the following system of equations:

$$
\begin{gathered}
\left(A-\Delta \mathrm{CO}_{2}-x_{1}\right)+\left(D+\Delta \mathrm{OH}^{-}-x_{3}-x_{2}-x_{1}\right) \leftrightarrow\left(B-x_{2}+x_{1}\right)+\left(F+x_{3}+x_{2}+x_{1}\right) \\
\left(B-x_{2}+x_{1}\right)+\left(D+\Delta \mathrm{OH}^{-}-x_{3}-x_{2}-x_{1}\right) \leftrightarrow\left(C+x_{2}\right)+\left(F+x_{3}+x_{2}+x_{1}\right) \\
\left(E-x_{3}\right)+\left(D+\Delta \mathrm{OH}^{-}-x_{3}-x_{2}-x_{1}\right) \leftrightarrow 2\left(F+x_{3}+x_{2}+x_{1}\right)
\end{gathered}
$$

By using the definition of each equilibrium constant, we reach the following relations:

$$
\begin{gathered}
\left(A-\Delta \mathrm{CO}_{2}-x_{1}\right)\left(D+\Delta \mathrm{OH}^{-}-x_{3}-x_{2}-x_{1}\right)=K_{b 1}\left(B-x_{2}+x_{1}\right) \\
\left(B-x_{2}+x_{1}\right)\left(D+\Delta \mathrm{OH}^{-}-x_{3}-x_{2}-x_{1}\right)=K_{b 2}\left(C+x_{2}\right) \\
\left(E-x_{3}\right)\left(D+\Delta \mathrm{OH}^{-}-x_{3}-x_{2}-x_{1}\right)=K_{w}
\end{gathered}
$$

The unknowns $x_{1}, x_{2}$ and $x_{3}$ are considered subtracting values of the hydroxide ion concentration since $\Delta \mathrm{OH}^{-}$is positive and the system tends to a bring that concentration down to the original level. $\Delta \mathrm{CO}_{2}$ is regarded as a subtracting value since the $\mathrm{CO}_{2}$ is only consumed and never produced. Equations (S22 - S24) form a system of three equations with three unknowns, which can be directly solved to obtain the corresponding equilibrating trend of each ion due to $\Delta \mathrm{OH}^{-}$and / or $\Delta \mathrm{CO}_{2}$. Results are shown in the main text in Figure 5. 


\section{Solution of the mass diffusion equation for $\mathrm{CO}_{2}$ depletion}

The diffusive mass transfer equation accounting for the $\mathrm{CO}_{2}$ transport in the electrolyte and neglecting the ionic transfer in the system reads as follows (Equations (6-8) in main text):

$$
\frac{\partial \Delta \mathrm{CO}_{2}}{\partial t}=D \frac{1}{r^{2}} \frac{\partial}{\partial r}\left(r^{2} \frac{\partial \Delta \mathrm{CO}_{2}}{\partial r}\right)
$$

with boundary conditions

$$
\begin{gathered}
\Delta \mathrm{CO}_{2}(t=0, r)=0 \\
\Delta \mathrm{CO}_{2}(t, r \rightarrow \infty)=0 \\
\left.\lim _{\varepsilon \rightarrow r_{e}} 2 \pi \varepsilon L D \frac{\partial \Delta \mathrm{CO}_{2}}{\partial r}\right|_{r \rightarrow \varepsilon}=\dot{m},
\end{gathered}
$$

with

$$
\dot{m}=\sum \dot{m}_{i}=\sum \frac{i_{\text {partial }, \mathrm{i}} M_{i}}{F z_{i}}=\sum \frac{i_{\text {total }} F_{\text {eff }, \mathrm{i}} M_{i}}{F z_{i}}=\frac{i_{\text {total }}}{F} \sum \frac{F_{\text {eff }, \mathrm{i}} M_{i}}{z_{i}} .
$$

Here, $D$ is the diffusion coefficient of $\mathrm{CO}_{2}$ in the $0.1 \mathrm{M} \mathrm{KHCO}_{3}$ solution ${ }^{23-25}, r$ is the radial coordinate with origin the center of the electrocatalyst coil, $r_{e}$ is the radius of the electrode wire and $\dot{m}$ is the mass consumption rate defined using Faraday's law, with $i$ the current, $F$ Faraday's constant, $F_{\text {eff }}$ the Faradaic efficiency, $M$ the molecular weight and $z$ the valence of the reaction. Subindex $i$ indicates the different products from CO2RR not including $\mathrm{H}_{2}$, as specified in the main text.

By means of defining dimensionless variables:

$$
X=\frac{r}{\sqrt{D t}} \quad Y=\frac{\Delta \mathrm{CO}_{2} \mathrm{Dr}}{\dot{m}}
$$

and substituting in the previous system, the partial differential equation becomes an ordinary differential equation:

$$
-\frac{1}{2} X \frac{d Y}{d X}=\frac{d^{2} X}{d X^{2}}
$$

with boundary conditions:

$$
\begin{gathered}
Y(X \rightarrow \infty)=0 \\
\lim _{\varepsilon \rightarrow r_{e}}\left(X \frac{d Y}{d X}-Y\right)=\frac{r_{e}}{2 \pi L}
\end{gathered}
$$

Following the same procedure as in Moreno Soto et al. ${ }^{26}$, the solution to the system is found:

$$
\Delta \mathrm{CO}_{2}=-\frac{\sqrt{\pi} r_{e} \dot{m}}{2 \pi L D r\left(\frac{r_{e}}{\sqrt{D t}} \exp \left(-\frac{r_{e}^{2}}{4 D t}\right)+\sqrt{\pi} \operatorname{erfc}\left(\frac{r_{e}}{2 \sqrt{D t}}\right)\right)} \operatorname{erfc}\left(\frac{r}{2 \sqrt{D t}}\right)
$$

This equation can be further simplified by acknowledging that $r_{e} / \sqrt{D t} \ll 1$ within the first 5 min of reaction. That way, the depletion model finally reads:

$$
\Delta \mathrm{CO}_{2}=-\frac{r_{e}}{2 \pi L D r} \dot{m} \operatorname{erfc}\left(\frac{r}{2 \sqrt{D t}}\right)
$$




\section{References}

[1] R. F. Silva, M. De Francesco, and A. Pozio. Solution-cast Nafion ionomer membranes: preparation and characterization. Electrochim. Acta, 49(19):3211-3219, 2004.

[2] K.-Y. Cho, H.-Y. Jung, K. A. Sung, W.-K. Kim, S.-J. Sung, J.-K. Park, J.-H. Choi, and Y.-E. Sung. Preparation and characteristics of Nafion membrane coated with a PVdF copolymer/recast Nafion blend for direct methanol fuel cell. J. Power Sources, 159(1):524-528, 2006.

[3] Q. Luo, H. Zhang, J. Chen, D. You, C. Sun, and Y. Zhang. Preparation and characterization of Nafion/SPEEK layered composite membrane and its application in vanadium redox flow battery. J. Membr. Sci., 325(2):553-558, 2008.

[4] R. Gloukhovski, V. Freger, and Y. Tsur. Understanding methods of preparation and characterization of pore-filling polymer composites for proton exchange membranes: a beginner's guide. Rev. Chem. Eng., 34(4):455-479, 2018.

[5] J. A. Moghaddam, M. J. Parnian, and S. Rowshanzamir. Preparation, characterization, and electrochemical properties investigation of recycled proton exchange membrane for fuel cell applications. Energy, 161:699-709, 2018.

[6] Y. Lum, B. Yue, P. Lobaccaro, A. T. Bell, and J. W. Ager. Optimizing C-C coupling on oxidederived copper catalysts for electrochemical $\mathrm{CO}_{2}$ reduction. J. Phys. Chem. C, 121(26):1419114203, 2017.

[7] E. Pircher, M. Ruíz Martínez, S. Hansal, and W. Hansal. Electropolishing of copper alloys in phosphoric acid solutions with alcohols. Plat. Surf. Finish., 90(5):74-79, 2003.

[8] A. Matikainen, T. Nuutinen, T. Itkonen, S. Heinilehto, J. Puustinen, J. Hiltunen, J. Lappalainen, P. Karioja, and P. Vahimaa. Atmospheric oxidation and carbon contamination of silver and its effect on surface-enhanced Raman spectroscopy (SERS). Sci. Rep., 6(37192):16, 2016.

[9] J. Qiu, J. Tang, J. Shen, C. Wu, M. Qian, Z. He, J. Chen, and S. Shuang. Preparation of a silver electrode with a three-dimensional surface and its performance in the electrochemical reduction of carbon dioxide. Electrochim. Acta, 203:99-108, 2016.

[10] M. R. Singh, Y. Kwon, Y. Lum, J. W. Ager, III, and A. T. Bell. Hydrolysis of electrolyte cations enhances the electrochemical reduction of $\mathrm{CO}_{2}$ over $\mathrm{Ag}$ and $\mathrm{Cu}$. J. Am. Chem. Soc., 138(39):13006-13012, 2016.

[11] Y. S. Ham, S. Choe, M. J. Kim, T. Lim, S.-K. Kim, and J. J. Kim. Electrodeposited Ag catalysts for the electrochemical reduction of $\mathrm{CO}_{2}$ to CO. Appl. Catal. B: Environ., 208:35-43, 2017.

[12] I. Katsounaros, W. B. Schneider, J. C. Meier, U. Benedikt, P. U. Biedermann, A. A. Auer, and K. J. J. Mayrhofer. Hydrogen peroxide electrochemistry on platinum: towards understanding the oxygen reduction reaction mechanism. Phys. Chem. Chem. Phys., 14(20):7384-7391, 2012.

[13] Á. Moreno Soto, S. R. German, H. Ren, D. van der Meer, D. Lohse, M. A. Edwards, and H. S. White. The nucleation rate of single $\mathrm{O}_{2}$ nanobubbles at Pt nanoelectrodes. Langmuir, 34:7309-7318, 2018.

[14] L. D. Burke and P. F. Nugent. The electrochemistry of gold: I. The redox behaviour of the metal in aqueous media. Gold Bull., 30(2):43-53, 1997. 
[15] L. D. Burke and P. F. Nugent. The electrochemistry of gold: II. The electrocatalytic behaviour of the metal in aqueous media. Gold Bull., 31(2):39-50, 1998.

[16] H. S. Harned and S. R. Scholes, Jr. The ionization constant of hco- from 0 to $50^{\circ}$. J. Am. Chem. Soc., 63(6):1706-1709, 1941.

[17] H. S. Harned and R. Davis, Jr. The ionization constant of carbonic acid in water and the solubility of carbon dioxide in water and aqueous salt solutions from 0 to $50^{\circ}$. J. Am. Chem. Soc., 65(10):2030-2037, 1943.

[18] A. G. Dickson and F. J. Millero. A comparison of the equilibrium constants for the dissociation of carbonic acid in seawater media. Deep Sea Res. Part A, 34(10):1733-1743, 1987.

[19] F. J. Millero and R. N. Roy. A chemical equilibrium model for the carbonate system in natural waters. Croat. Chem. Acta, 70(1):1-38, 1997.

[20] W. Henry. Experiments on the quantity of gases absorbed by water, at different temperatures, and under different pressures. Philos. Trans. R. Soc. London, 93:29-42+274-276, 1803.

[21] A. Bejan. Heat transfer. John Wiley and Sons, Inc., first edition, 1993.

[22] P. Peñas, P. van der Linde, W. Vijselaar, D. van der Meer, D. Lohse, J. Huskens, H. Gardeniers, M. A. Modestino, and D. Fernández Rivas. Decoupling gas evolution from water-splitting electrodes. J. Electrochem. Soc., 166(15):H769-H776, 2019.

[23] C. R. Wilke and P. Chang. Correlation of diffusion coefficients in dilute solutions. AIChE J., 1(2):264-270, 1955.

[24] M. J. W. Frank, J. A. M. Kuipers, and W. P. M. van Swaaij. Diffusion coefficients and viscosities of $\mathrm{CO}_{2}+\mathrm{H}_{2} \mathrm{O}, \mathrm{CO}_{2}+\mathrm{CH}_{3} \mathrm{OH}, \mathrm{NH}_{3}+\mathrm{H}_{2} \mathrm{O}$, and $\mathrm{NH}_{3}+\mathrm{CH}_{3} \mathrm{OH}$ liquid mixtures. J. Chem. Eng. Data, 41(2):297-302, 1996.

[25] G. Liger-Belair, E. Prost, M. Parmentier, P. Jeandet, and J.-M. Nuzillard. Diffusion coefficient of $\mathrm{CO}_{2}$ molecules as determined by ${ }^{13} \mathrm{C}$ NMR in various carbonated beverages. J. Agric. Food Chem., 51(26):7560-7563, 2003.

[26] Á. Moreno Soto, A. Prosperetti, D. Lohse, and D. van der Meer. Gas depletion through single gas bubble diffusive growth and its effect on subsequent bubbles. J. Fluid Mech., 831:474-490, 2017. 